\title{
Macronutrient consumption prior to, and during, a mountain marathon
}

\author{
Elizabeth Mahon ${ }^{1}$, Allan Hackett ${ }^{1}$, Timothy Stott ${ }^{1}$, Keith George ${ }^{2}$, Ian Davies ${ }^{1}$ \\ ${ }^{1}$ Faculty of Education, Health and Community, Liverpool John Moores University, Liverpool, United Kingdom \\ ${ }^{2}$ Research Institute for Sport and Exercise Sciences, Liverpool John Moores University, Liverpool, United Kingdom
}

\section{Email address:}

E.Haywood@ljmu.ac.uk (E. Mahon)

\section{To cite this article:}

Elizabeth Mahon, Allan Hackett, Timothy Stott, Keith George, Ian Davies. Macronutrient Consumption Prior to, and during, a Mountain Marathon. American Journal of Sports Science. Vol. 2, No. 1, 2014, pp. 5-12. doi: 10.11648/j.ajss.20140201.12

\begin{abstract}
Participation in ultra-endurance events such as mountain marathons is increasing, yet analysis of the nutritional intake and requirements of this group of athletes have received relatively little attention. This field study examined athletes' food intake prior to, and during a mountain marathon event to assess compliance with recommendations and to identify associations with performance. Nineteen male athletes competing in the Longmynd Hike (LH) completed a 7-day food diary in the week prior to the event and a weighed food inventory of all items consumed during the event. Despite reported intentions to increase carbohydrate $(\mathrm{CHO})$ consumption in the week prior to the event, there was no significant change in consumption across the week. The mean daily $\mathrm{CHO}$ intake of $4.5 \mathrm{~g} / \mathrm{kg} / \mathrm{d}$ was below that recommended to effectively enhance glycogen stores. $\mathrm{CHO}$ and energy consumption prior to the event were positively associated with performance [energy $(\mathrm{kJ} / \mathrm{kg} / \mathrm{d}): r=.56, p=0.03 ; \mathrm{CHO}(\mathrm{g} / \mathrm{kg} / \mathrm{d}): r=.54, p=0.04]$. Energy and CHO consumption during the event were also positively correlated with performance [energy $(\mathrm{kJ} / \mathrm{kg} / \mathrm{h}): r=.80, p<0.001 ; \mathrm{CHO}(\mathrm{g} / \mathrm{kg} / \mathrm{h}): r=.75, p=0.001)]$, despite most participants again failing to meet recommendations for intake. Further research is needed to determine reasons for non-compliance with nutritional guidelines and to investigate to what extent type and timing of macronutrient intake during such events impacts on performance.
\end{abstract}

Keywords: Ultra-Endurance, Exercise, Carbohydrate, Fat, Running, Hill-Walking

\section{Introduction}

The popularity of ultra-endurance sport, both as a leisure time activity and in competitive events, is rising [1]. Popular ultra-endurance races in the United Kingdom (UK) include mountain marathons, which are typically either two-day (with a mid-camp) or continuous races combining fell-running and orienteering over steep, uneven terrain [2]. They can either be supported, where food and drink is provided at aid stations, or unsupported in which participants must carry their own provisions. The prolonged duration of such events and additional factors; such as weather conditions, backpack weight and severity of terrain can result in exceptional physiological and metabolic demands being placed on the competitors [3]. Consequently, the nutritional requirements of these athletes are likely very important to health and performance but have received little attention.

Maintaining an energy supply to meet the physiological demands of prolonged exercise is paramount to performance [4-5], and several strategies exist to accomplish this. Supercompensating muscle glycogen levels by carbohydrate $(\mathrm{CHO})$ loading in the days prior to an endurance event can improve performance by $2-3 \%$ [6]. Secondly, convincing evidence from numerous studies now indicates that $\mathrm{CHO}$ ingestion during exercise of one hour or more can improve work capacity and performance [7-10]. The American College of Sports Medicine (ACSM) recommends intakes of $30-60 \mathrm{~g} / \mathrm{h}$ of $\mathrm{CHO}$ during endurance exercise [11], whilst the latest International Olympic Committee (IOC) consensus statement on sports nutrition 2010 [12] advises that athletes participating in events lasting $>2.5 \mathrm{~h}$ may benefit from higher intakes up to $90 \mathrm{~g} / \mathrm{h}$. Other strategies include utilizing fat as an alternative fuel to attempt to enhance rates of fat oxidation during exercise and reduce rates of muscle glycogen use [13-14]. Studies on prolonged low-moderate intensity exercise have shown an enhanced fat oxidation to be the major energy source [15-16].

It is evident that nutritional strategies are very dependent 
on the format of the race to be completed and in particular the intensities of exercise involved. An important feature of the mountain marathon is the varying intensity at which athletes must work. Whilst no study has measured percentages of maximal oxygen uptake $\left(\mathrm{VO}_{2} \max \right)$ during mountain marathon events, studies performed on hill walkers have shown that they typically work at a range of $25-70 \% \mathrm{VO}_{2} \max$ [17]. Mountain marathoners are likely to reach higher intensities due to the competitive nature of the sport, and so such events are examples of where a mix of nutritional strategies may be required.

To date very few studies have investigated the dietary practices of mountain marathon competitors [2,18-19]. Kruesman et al. observed the fluid and fuel intake of 42 amateur runners in a $44 \mathrm{~km}$ Swiss mountain marathon [18]. Mean hourly intakes of energy, $\mathrm{CHO}$, fat and protein were $590 \mathrm{~kJ}, 31 \mathrm{~g}, 2 \mathrm{~g}$ and $0.8 \mathrm{~g}$, respectively. Whilst the mean $\mathrm{CHO}$ intake was within the recommended range provided by the ACSM [11], more than half the runners were unable to meet energy balance and accumulated a deficit of between $7,908-10,341 \mathrm{~kJ}$ during the race. It is hypothesized in an unsupported race, where runners must carry their own food; even greater energy deficits would be observed. Clarke et al. recorded the nutrient intakes of 90 athletes competing across four different two-day unsupported mountain marathon events in the UK [2]. Nutrient data are not provided on a $\mathrm{g} / \mathrm{h}$ basis and so cannot be compared to current guidelines, but $\mathrm{g} / \mathrm{kg} / \mathrm{h}$ of athletic effort for energy, $\mathrm{CHO}$, fat and protein were $20.67 \mathrm{~kJ}, 0.89$ $\mathrm{g}, 0.11 \mathrm{~g}$ and $0.10 \mathrm{~g}$, respectively. It is clear that $\mathrm{CHO}$ consumption was below that required to reach maximal oxidation rates. Energy expenditure was not calculated and as no indication of distance or time taken to complete the course was provided, it is difficult to estimate energy balance. Performance was positively associated with energy, $\mathrm{CHO}$ and protein intake. Stuempfle et al. analyzed the race diet of competitors in the Western States Endurance Run; a $161 \mathrm{~km}$ supported mountain footrace [19]. They compared the nutrient intakes of those who finished compared to the non-finishers and found significantly higher intakes of overall energy $(4.6 \pm 1.7$ vs. $2.5 \pm 1.3 \mathrm{kcal} / \mathrm{kg} / \mathrm{h}), \mathrm{CHO}(0.9$ \pm 0.43 vs. $0.56 \pm 0.32 \mathrm{~g} / \mathrm{kg} / \mathrm{h})$ and fat $(0.06 \pm 0.03$ vs. 0.02 $\pm 0.02 \mathrm{~g} / \mathrm{kg} / \mathrm{h})$, respectively. However, the sample sizes were very small; only six participants finished the race and there was large variation in the nutrient intakes.

It is evident that there are few detailed reports of nutrient intakes in mountain marathoners. Whilst $\mathrm{CHO}$ appears to be beneficial to performance during such events, there are no existing accounts of nutrient consumption prior to events with regard to whether high-CHO or high-fat diets are optimal. Further research is therefore warranted in this area to determine optimal strategies. The main objective of this study was to provide descriptive information on the food intakes of athletes prior to, and during, a continuous unsupported mountain marathon event to assess compliance with recommendations and to identify associations with performance. Secondary objectives were to record athletes' intended race-diet strategies in order to explore whether these led to appropriate nutrient intakes; determine whether nutrient intake differed depending on age and experience; and to measure blood $\beta$-ketones to provide an objective measure of energy metabolism and macronutrient utilization during the event.

\section{Method}

\subsection{Setting}

The event used for this study was the Longmynd Hike (LH), held in October 2009. The LH is an $80.5 \mathrm{~km}$ continuous, competitive mountain marathon set in the countryside of South Shropshire and the Welsh Marches UK, with approximately 2,400 $\mathrm{m}$ of climbing over eight summits. The course profile is displayed in Fig. 1. No food was provided and so competitors were required to carry sufficient food for the duration of the event. The event attracts a wide spectrum of competitors ranging from elite fell-runners to recreational athletes. This event was chosen, as previous studies on mountain marathons have either used two-day events [2], which make interpretation of dietary intake and association with performance difficult, or supported events [18-19]. An unsupported event was used as larger differences in food selection and energy consumption are likely to be seen. Weight of food carried is a concern for competitors and as a result food intake might be restricted [2].

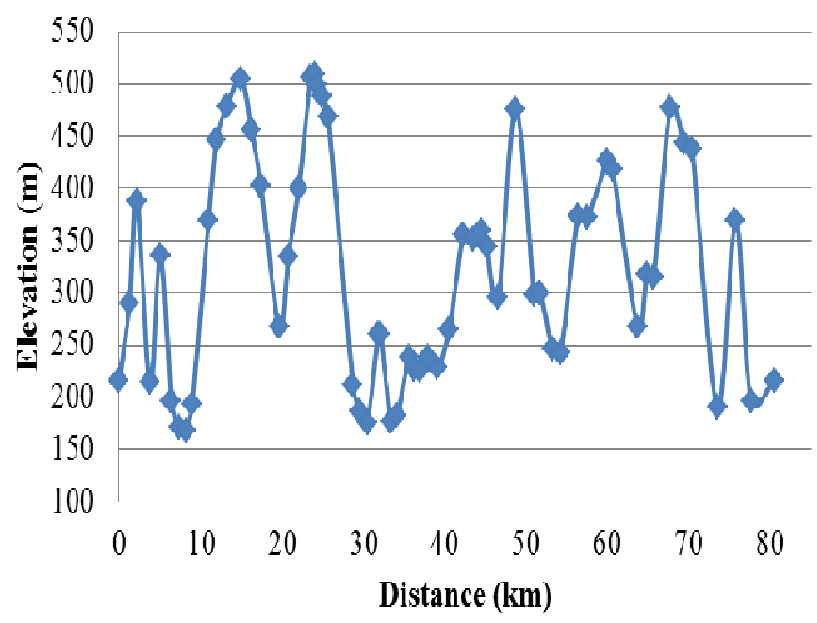

Figure 1. Longmynd Hike course profile (plotted from course data available on the event website [20]).

\subsection{Participants}

Ethical approval was granted by Liverpool (Adult) Research Ethics Committee and Liverpool John Moores University Ethics Committee. Competitor participants were recruited through links on the event website and flyers sent out with entry packs. Volunteers registered their intent to participate via email and consent to take part in the different elements of the study was obtained in writing. 


\subsection{Protocol and Procedures}

Self-administered questionnaires were sent to all participants prior to the event to collect data on participant characteristics; dietary habits prior to and during previous ultra-endurance events; and level of experience in mountainous environments and in ultra-endurance racing.

\subsubsection{Food Intake and Analysis}

Dietary intake was assessed with a seven-day weighed food diary in the week prior to the event. To record consumption during the event participants were asked to compile an inventory (at home prior to the event) of all the food (including sports drinks) which they had packed to take with them. They were provided with a proforma to complete which asked them to provide a detailed description of the foods and the weight (in grams) of each food item. On arrival at the event headquarters on the day of the race, participants were asked to present their paperwork to a researcher who checked that it was complete, questioned any ambiguities and added detail where necessary on the food diary and food inventory forms. After the event, any leftover food was weighed by the researchers on site and net consumption was calculated and inputted onto the food inventory forms. Leftover food was weighed using digital scales accurate to $1 \mathrm{~g}$.

Food data and macronutrient intakes were analyzed using dietary software (MicroDiet, version 1.2). The macronutrient content was taken from standard food tables [21], available datasets on the MicroDiet software programme, or specialist items were inputted manually using information collected from food labels provided by participants or product websites.

\subsubsection{Anthropometrics}

The body mass (BM) and pack weight of each participant was recorded using calibrated scales accurate to $0.1 \mathrm{~kg}$. Height was measured using a stadiometer to the nearest $1 \mathrm{~mm}$. Measurements were performed to standard protocol on the morning of the event.

\subsubsection{Blood Analyses}

Blood $\beta$-ketones were measured as an indicator of energy metabolism and macronutrient utilization. Levels of $\beta$-ketones below $0.6 \mathrm{mmol} / \mathrm{L}$ are considered normal and those over $1.5 \mathrm{mmol} / \mathrm{L}$ elevated. In this study $\beta$-ketones were measured from a fresh capillary whole blood sample taken from the fingertip and analyzed using the MediSense $\left(\right.$ Optium $\left.^{\mathrm{TM}}\right)$ instrument. Precision and accuracy testing shows that results typically vary by no more than $3.1-$ $3.8 \%$ coefficient of variation [22]. Measurements were taken pre- and post-event. Participants were asked to report to the testing area, a room at the event headquarters, as soon as they had completed the event.

\subsubsection{Performance}

Performance was calculated as a reciprocal percentage of the winning time [2], times were age-adjusted:
200 - (Individual time / winning time x 100)

\subsection{Statistical Procedures}

Statistical analyses were performed with SPSS (version 17.0). Descriptive statistics (mean, standard deviation (SD), minimum, maximum) were calculated for completion time, participant characteristics, nutrient intakes and blood ketones. Frequencies were reported for questionnaire responses and number of participants meeting dietary recommendations. All data were tested for normality and non-parametric tests were used where appropriate.

A one-way repeated measures ANOVA explored the differences in $\mathrm{CHO}$ consumption during the week prior to the event and the Wilcoxon Signed Rank Test was used to detect significant changes in blood ketone levels. Associations between various aspects of dietary intake, participant characteristics and performance were tested with Pearson's and Spearman's rank correlation coefficients and a standard multiple linear regression model, with factors statistically associated with performance, was employed to determine the best predictor of performance. All tests were two-tailed, with alpha $<0.05$.

\section{Results}

\subsection{Participant Characteristics}

Nineteen male participants volunteered from the 550 registered for the LH. The sample was split into the following age categories to reflect the classes that athletes compete in: 'male' 18 - $39 \mathrm{y}$; 'male senior' $40-49 \mathrm{y}$; and 'male veteran' $50+$ y. Sample characteristics were as follows: $n=19$; age ( $18-39$ y: $n=5,40-49 \mathrm{y}: n=7,50+$ y: $n=7)$; BM: 76.3 (10.3) kg; body mass index (BMI); $24.3(3.3) \mathrm{kgm}^{-2}$; and course completion time $16( \pm 3) \mathrm{h}$.

The majority of participants (18/19) had previously taken part in the same event before. Experience can be important to performance in such events and so was classified as the number of times participants have previously taken part in the event. The sample was split as follows: 'never or once' $(n=7)$; ' 2 to 5 times' $(n=8)$; and 'more than 5 ' $(n=4)$.

\subsection{Food Intake in the Week Prior to the Event}

On the pre-event questionnaire $95 \%$ of all participants commented that food consumed in the week prior to an event can impact on performance, with $78 \%$ claiming to have changed their diet in the past to aid performance. The main dietary change reported was an increase in $\mathrm{CHO}$ consumption ( $86 \%$ ). Regarding the targeted event, $74 \%$ of participants reported planning to change their diet with $86 \%$ of these planning to increase their $\mathrm{CHO}$ intake. Only one participant planned to increase their fat consumption.

Macronutrient intakes are presented in Table 1. There was no difference in nutrient consumption with respect to age, and no noteworthy differences with respect to experience when taking BM into account. There was however, considerable between-participant variation. 
Consequently all further analyses represent the entire cohort (with age and experience groups collapsed). Despite reported intentions to increase $\mathrm{CHO}$ consumption, there was no significant change in $\mathrm{CHO}$ consumption throughout the week (Table 2).

Table 1. Mean macronutrient consumption prior to the event

\begin{tabular}{ccc}
\hline Nutrient & Mean (SD) & Range \\
\hline Energy $(\mathrm{kJ} / \mathrm{kg} / \mathrm{d})$ & $145(39)$ & $77-238$ \\
$\mathrm{CHO}(\mathrm{g} / \mathrm{kg} / \mathrm{d})$ & $4.5(1.1)$ & $2.3-6.8$ \\
Protein $(\mathrm{g} / \mathrm{kg} / \mathrm{d})$ & $1.3(0.4)$ & $0.7-1.9$ \\
Fat $(\mathrm{g} / \mathrm{kg} / \mathrm{d})$ & $1.3(0.4)$ & $0.7-2.3$ \\
\hline
\end{tabular}

Table 2. CHO intake in the week prior to the event

\begin{tabular}{ccc}
\hline \multirow{2}{*}{ Day of food diary } & \multicolumn{2}{c}{ CHO $(\mathbf{g} / \mathbf{k g} / \mathbf{d})$} \\
& Mean (SD) & Range \\
\hline & & \\
\hline 1 & $4.6(1.5)$ & $2.2-7.5$ \\
2 & $4.7(1.6)$ & $2.8-8.7$ \\
3 & $3.9(1.6)$ & $1.6-7.5$ \\
4 & $4.4(1.8)$ & $2.0-9.9$ \\
5 & $4.5(1.6)$ & $1.8-8.4$ \\
6 & $4.6(1.7)$ & $2.5-8.0$ \\
7 & $4.9(1.4)$ & $2.3-7.7$ \\
\hline
\end{tabular}

\subsection{Food Intake During the Event}

All participants reported that food consumed during the event has some influence on performance. A wide range of food stuffs were consumed, both specialized sports products and traditional foods (see table 3 for full details). Sports products included: sports drinks; energy gels; energy bars; and energy tablets. Such products were used by $74 \%$ of competitors contributing from 0 to $97 \%$ of total energy. Popular traditional snack products included: cereal bars; chocolate; dried fruit; nuts and jelly babies.

Table 3. Popular food items consumed during the event

\begin{tabular}{cc}
\hline Food item & Number of participants who consumed \\
\hline Chocolate & 13 \\
Sandwich & 12 \\
Energy gel & 11 \\
Dried fruit & 11 \\
Energy/sports bar & 10 \\
Banana & 10 \\
Energy/sports drink & 10 \\
Nuts & 10 \\
Cereal/muesli bar & 9 \\
Energy tablets & 9 \\
Sweets (jelly babies) & 9 \\
Malt loaf & 7 \\
Pasta & 4 \\
\hline
\end{tabular}

Energy and macronutrient intake is shown in table 4. Total nutrient intake data was divided by the number of hours on the course to give hourly estimates. Nutrient intake data did not vary with age or experience. The mean hourly $\mathrm{CHO}$ consumption was $28( \pm 17) \mathrm{g} / \mathrm{h}$.

Table 4. Mean macronutrient consumption during the event

\begin{tabular}{ccc}
\hline Nutrient & Mean (SD) & Range \\
\hline Total Energy $(\mathrm{kJ})$ & $9827(3458)$ & $5396-15975$ \\
Total CHO $(\mathrm{g})$ & $413(195)$ & $197-932$ \\
Total Protein $(\mathrm{g})$ & $57(43)$ & $13-186$ \\
Total Fat $(\mathrm{g})$ & $61(31)$ & $11-125$ \\
Energy $(\mathrm{kJ} / \mathrm{kg} / \mathrm{h})$ & $8.7(4.4)$ & $2.5-16.7$ \\
CHO $(\mathrm{g} / \mathrm{kg} / \mathrm{h})$ & $0.4(0.3)$ & $0.08-1.0$ \\
Protein $(\mathrm{g} / \mathrm{kg} / \mathrm{h})$ & $0.05(0.04)$ & $0.02-0.19$ \\
Fat $(\mathrm{g} / \mathrm{kg} / \mathrm{h})$ & $0.05(0.03)$ & $0.01-0.13$ \\
Energy density $(\mathrm{kJ} / \mathrm{g})$ & $12(3)$ & $9-20$ \\
Total food carried $(\mathrm{g})$ & $854(405)$ & $282-1780$ \\
\hline
\end{tabular}

\subsection{Blood $\beta$-Ketone Levels}

Blood $\beta$-ketones significantly increased during the event (Fig. 2). There was a significant increase from pre $[M d=$ $0.00(0.00-0.00) \mathrm{mmol} / \mathrm{L}]$ to post $[M d=0.90(0.35-1.15)$ $\mathrm{mmol} / \mathrm{L}]$ event $(z=-3.63, p<0.001, n=17)$. Those consuming less $\mathrm{CHO}$ tended to have higher post-ketone levels $(\mathrm{CHO}<30 \mathrm{~g} / \mathrm{h}: n=11$, mean post $\beta$-ketones $=1.24( \pm$ 1.0) $\mathrm{mmol} / \mathrm{L}$; CHO 30-60 g/h: $n=3$, mean post $\beta$-ketones $=$ $0.63( \pm 0.4) \mathrm{mmol} / \mathrm{L} ; \mathrm{CHO}>60 \mathrm{~g} / \mathrm{h}: n=1$, post $\beta$-ketones $=$ $0.30 \mathrm{mmol} / \mathrm{L})$. Correlation analysis showed a significant negative relationship between post-ketones and performance (Table 5).

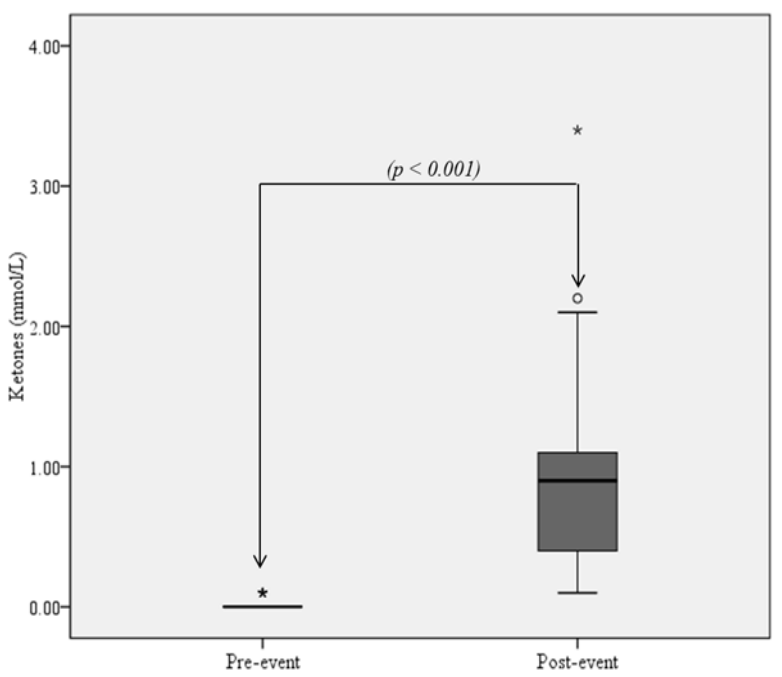

Figure 2. Change in blood $\beta$-ketone levels during the event (o indicates outliers, * indicates outliers that are more than three box-lengths from the edge of the box). 
Table 5. Correlation coefficients showing association with performance $\left({ }^{*} p<0.05,{ }^{* *} p<0.01,{ }^{* * *} p<0.001\right)$

\begin{tabular}{|c|c|c|}
\hline & Nutrient & Performance \\
\hline \multirow{4}{*}{$\begin{array}{l}\text { Nutrient intake in the } \\
\text { week prior }\end{array}$} & Energy $(\mathrm{kJ} / \mathrm{kg} / \mathrm{d})$ & $0.56^{*}$ \\
\hline & $\mathrm{CHO}(\mathrm{g} / \mathrm{kg} / \mathrm{d})$ & $0.54 *$ \\
\hline & Protein $(\mathrm{g} / \mathrm{kg} / \mathrm{d})$ & 0.38 \\
\hline & Fat $(\mathrm{g} / \mathrm{kg} / \mathrm{d})$ & 0.43 \\
\hline \multirow{5}{*}{$\begin{array}{l}\text { Nutrient intake } \\
\text { during the event }\end{array}$} & Energy $(\mathrm{kJ} / \mathrm{kg} / \mathrm{h})$ & $0.80^{* * *}$ \\
\hline & $\mathrm{CHO}(\mathrm{g} / \mathrm{kg} / \mathrm{h})$ & $0.75^{* *}$ \\
\hline & Protein $(g / k g / h)$ & 0.39 \\
\hline & Fat $(\mathrm{g} / \mathrm{kg} / \mathrm{h})$ & 0.46 \\
\hline & Energy density $(\mathrm{kJ} / \mathrm{g})$ & 0.07 \\
\hline \multirow{4}{*}{ Other predictors } & $\begin{array}{l}\text { Post-event } \beta \text {-ketones } \\
(\mathrm{mmol} / \mathrm{L})\end{array}$ & $-0.60 *$ \\
\hline & $\mathrm{BM}(\mathrm{kg})$ & $-0.65^{* *}$ \\
\hline & $\operatorname{BMI}\left(\mathrm{kgm}^{-2}\right)$ & $-0.55^{*}$ \\
\hline & Pack weight (kg) & -0.46 \\
\hline
\end{tabular}

\subsection{Predictors of Performance}

Both total energy and $\mathrm{CHO}$ consumed in the week prior to the LH were positively associated with performance when adjusted for BM (Table 5, Fig. 3). No such associations were seen with the other macronutrients. CHO consumption $(\mathrm{g} / \mathrm{kg} / \mathrm{d})$ on days 4,6 and 7 was also significantly associated with performance (Day 4: $r=.57, p=0.03$; Day 6: $r=.59, p$ $=0.02$; Day $7: r=.61, p=0.02, n=16$ ).

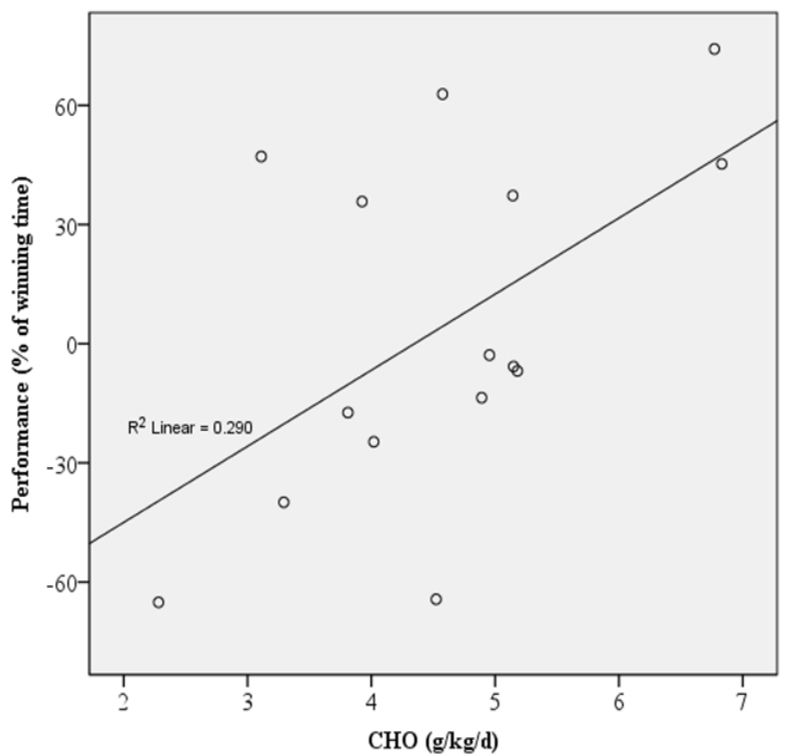

Figure 3. Relationship between $\mathrm{CHO}$ consumed in the week prior and performance

Energy and $\mathrm{CHO}$ consumed during the event also showed significant positive correlations with performance (Table 5, Fig. 4). No significant correlations were observed between fat, protein or energy density and performance. Asides from nutrient intake, lower BM and BMI were also associated with better performance.

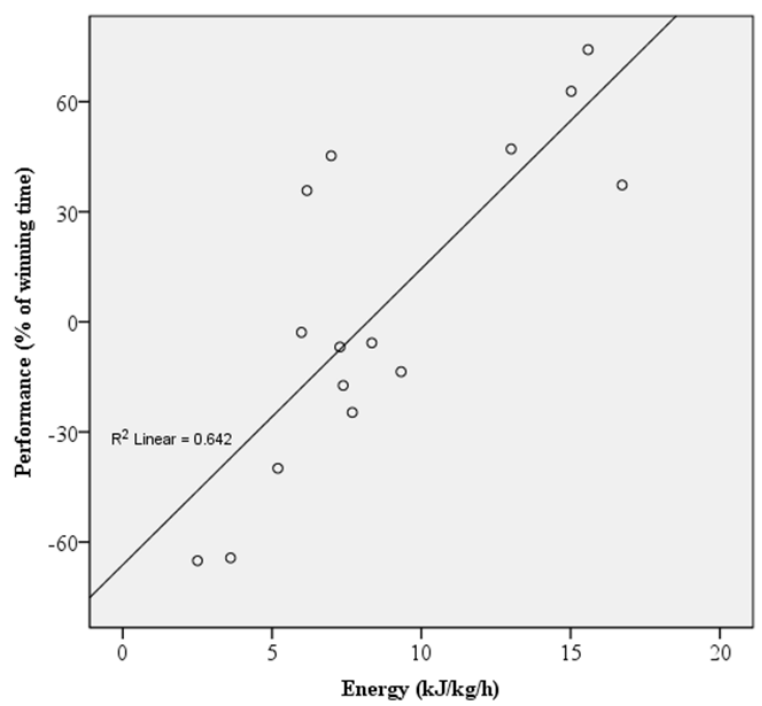

Figure 4. Relationship between energy consumed during the event and performance

Table 6 shows results from the multiple regression analysis that was performed for those variables that were associated with performance. The model performed suggests that together these variables explain $69 \%\left(\mathrm{R}^{2}\right.$ $=.693$ ) of the variance in performance, with energy consumed during the event $(\mathrm{kJ} / \mathrm{kg} / \mathrm{h})$ making a statistically significant unique contribution to performance $($ beta $=1.10$, $p=0.037)$.

Table 6. Linear regression model for performance $\left({ }^{*} p<0.05\right)$

\begin{tabular}{cccc}
\hline \multicolumn{4}{c}{ Model Summary: $\mathrm{R}^{2}=.693$, Adjusted $\mathrm{R}^{2}=.522$} \\
\hline Variable & $\begin{array}{c}\text { Regression } \\
\text { coefficient (beta) }\end{array}$ & $\boldsymbol{t}$ & $\boldsymbol{p}$ \\
\hline Energy prior $(\mathrm{kJ} / \mathrm{kg} / \mathrm{d})$ & -.128 & -.302 & .770 \\
CHO prior $(\mathrm{g} / \mathrm{kg} / \mathrm{d})$ & .428 & .965 & .360 \\
Energy during $(\mathrm{kJ} / \mathrm{kg} / \mathrm{h})$ & 1.096 & 2.452 & $.037^{*}$ \\
$\mathrm{CHO}$ during $(\mathrm{g} / \mathrm{kg} / \mathrm{h})$ & -.735 & -1.619 & .140 \\
BMI $\left(\mathrm{kgm}^{-2}\right)$ & -.301 & -1.085 & .306 \\
\hline
\end{tabular}

\section{Discussion}

\subsection{Nutrient Intake in the Week Prior to the Event}

Energy consumption in the week prior to the event (145 $\mathrm{kJ} / \mathrm{kg} / \mathrm{d}$, Table 1) was lower than that observed in other studies measuring energy intake from 7-day food diaries in male endurance athletes. Intakes of $280 \mathrm{~kJ} / \mathrm{kg} / \mathrm{d}$ have been previously reported for self-reported adequate eaters and $180 \mathrm{~kJ} / \mathrm{kg} / \mathrm{d}$ for small eaters [23], and intakes of $230 \mathrm{~kJ} / \mathrm{kg} / \mathrm{d}$ for Australian marathon runners [24]. However, the athletes in these studies were highly-trained and presumably 
undertaking larger quantities of training than the recreational athletes in the present study. In order to determine the extent of under-reporting, energy expenditure would need to be measured. It is important to note though that the athletes in the present study were volunteers and are therefore likely to be highly motivated and want to receive valuable feedback, which should limit conscious under-reporting.

Mean CHO intakes for the week were below the recommended $5-7 \mathrm{~g} / \mathrm{kg} / \mathrm{d}$ to meet the daily fuel needs of an athlete with a moderate training programme [25]. Despite over $65 \%$ of athletes reporting that they intended to increase their $\mathrm{CHO}$ intake in the week prior to the event, no participants came close to the CHO-loading recommendations of $10-12 \mathrm{~g} / \mathrm{kg} / \mathrm{d}$ in the 48 hours leading up to the event [25]. This is in line with findings from a previous study which reported that whilst $\mathrm{CHO}$-loading is a well-known term, athletes in real-life often fail to reach daily CHO targets needed to maximize glycogen storage [26]. Similar findings were reported in a study observing the dietary intakes of cyclists prior to, and during, a $210 \mathrm{~km}$ cycle race [27]. They noted that the mean self-reported CHO intake of forty-five cyclists in the three days leading up to the race was just $5.6 \pm 1.7 \mathrm{~g} / \mathrm{kg} / \mathrm{d}$. Regarding alternative strategies, there was no indication in the present study of chronic high-fat diets with no participants meeting high-fat protocols published in previous research $(2.6 \mathrm{~g} / \mathrm{kg} / \mathrm{d})$ [28].

Both energy and $\mathrm{CHO}$ were positively associated with performance. These findings support those from controlled, intervention studies that have shown $\mathrm{CHO}$ loading can improve performance [6], and provides evidence that higher intakes of $\mathrm{CHO}$ can be beneficial in a 'real-life' setting. Results indicated that $\mathrm{CHO}$ consumption, particularly in the latter half of the week was more important to performance than earlier in the week. This supports the guidelines that shorter CHO loading protocols should be sufficient [29-30]. This is an important message for athletes since they appear to struggle to consume the amounts recommended.

\subsection{Nutrient Intake During the Event}

The mean overall energy consumption during the event $(9,827 \mathrm{~kJ})$ appears low. Energy expenditure was not calculated during this study, due to financial constraints and the difficulties in accurately measuring this in the field. However, a study carried out measuring energy expenditure by the doubly labelled water technique over ten consecutive days of hill-walking reported values of approximately $21,000 \mathrm{~kJ} /$ day [31]. Given the distances covered in the hill-walking study ranged from $10-35 \mathrm{~km}$ per day, and the distances in the present study were substantially higher, it is likely that the participants in the present study were in significant negative energy balance. This appears to be the case in many ultra-endurance studies; during an ironman triathlon endogenous fuel stores contributed to half or more of the total energy requirements of the athletes [5].

Energy intake was positively associated with performance during the event. This finding is similar to those reported by others observing similar races $[2,18]$. This suggests that negative energy balance is detrimental, but further evidence is warranted.

Endurance athletes are advised to consume at least 30-60 $\mathrm{g} / \mathrm{h}$ of $\mathrm{CHO}$ during exercise [11], and up to $90 \mathrm{~g} / \mathrm{h}$ for exercise lasting longer than 2.5 hours [12]. The average intake in this sample was just $28 \mathrm{~g} / \mathrm{h}$. On an individual basis eleven participants consumed $<30-60 \mathrm{~g} / \mathrm{h}$, four within the range and one participant higher. Adjusting for BM, only three participants met the $0.5-1 \mathrm{~g} / \mathrm{kg} / \mathrm{h}$ recommendation for $\mathrm{CHO}$ consumption during prolonged moderate-intensity exercise [32]. A similar mean intake of $31 \mathrm{~g} / \mathrm{h}$ was reported in a Swiss mountain marathon, with over half the runners not meeting the minimal recommendation [18]. Other studies involving ultra-marathon running have reported slightly higher intakes; a mean figure of $43 \mathrm{~g} / \mathrm{h}$ was published from seven subjects during a $100 \mathrm{~km}$ road running race [33]. Literature available on ultra-endurance exercise suggests that athletes struggle to meet these requirements unless other disciplines are included, for example: intakes of $69 \mathrm{~g} / \mathrm{h}$ have been observed during an ironman triathlon [5], with the majority being consumed during the cycle leg; $63 \mathrm{~g} / \mathrm{h}$ in male cyclists during a $210 \mathrm{~km}$ race [27]; and $52 \mathrm{~g} / \mathrm{h}$ during a $384 \mathrm{~km}$ cycling event [34]. In order to meet the CHO demand during running events, the form of foods consumed and their mode of consumption requires further investigation.

As reported by Clark et al. [2], countless other studies performed on endurance exercise of shorter duration [10], and several cycling ultra-endurance events [27,34], $\mathrm{CHO}$ intake was positively associated with performance. This suggests that despite the potentially lower exercise intensity in such an event, $\mathrm{CHO}$ is the most important substrate to fuel the activity. In addition, those consuming sub-optimal amounts of $\mathrm{CHO}$ had higher levels of blood $\beta$-ketones post-event and post-blood $\beta$-ketone levels were negatively associated with performance, this further supports the need for $\mathrm{CHO}$ intake during prolonged events, given that ketones are an indicator of fat metabolism. During periods of glucose deficiency, such as fasting or prolonged exercise, ketone bodies can play a key role in sparing glucose utilization [35]. In a study performed on post-exercise ketosis it was found that whilst training status had no effect on post exercise ketone levels, diet prior to exercise did [36]. High-CHO diets were shown to prevent the onset of post-exercise ketonaemia whilst low-CHO diets enhanced it. The highest post-exercise ketone levels $(3.88 \mathrm{mmol} / \mathrm{L})$ were recorded in marathon runners following a glycogen-stripping regimen [36].

Other predictors of performance included BMI and BM. A key factor in performance may be leanness; however estimating body composition in the field is problematic. Conversely, lower BMI may reflect training status. Linear multiple regression analysis suggested that overall energy intake during the event was the best predictor of performance, stronger than physical characteristics, such as BMI, and nutrition in the week prior to the event. This suggests that advice should focus on increasing energy 
intake during such events, and in particular energy from $\mathrm{CHO}$. Further research is needed regarding the type of $\mathrm{CHO}$ consumed and timing of intake.

\subsection{Limitations}

There are several limitations to this study. Having no measures of physical activity in the week prior to the event makes it difficult to measure the accuracy of the food diaries. It is likely that a certain degree of underreporting of dietary intake exists. Nutrient intake data during the event from the food inventory form, however, is likely to be more accurate. Food items consumed were known prior to the race and participants had time to note down details of the products they were taking with them. Food items listed on the inventory were checked by a researcher prior to the event and all leftover food was weighed on completion. It would have been useful to have a measure of energy expenditure though, so that the energy balance status of athletes could have been accurately assessed.

The sample size was small, given the total number of runners in the event, but is comparable to those in other field studies of similar design [5,33-34]. Finally, being a cross-sectional, observational study, no causal relationship can be drawn between intake and performance and various factors that could be contributing to performance are missing, such as measures of fitness, body composition and hydration status.

\section{Conclusions}

The present study shows that a range of foods, both specialized sports products and traditional whole-foods are consumed by athletes taking part in mountain marathons. Whilst CHO and energy intakes both prior, and in particular during the event, appear to be beneficial to performance, the intakes of athletes in this sample were below current recommendations for endurance athletes. Whilst the possibility of under-reporting exists regarding the pre-event food diaries, nutrient intake data obtained during the event is likely to have good accuracy. It can therefore be concluded with some certainty that participants were consuming suboptimal amounts of energy and $\mathrm{CHO}$ during the race. Reasons for this could be: lack of knowledge of recommendations; inadequate practical nutrition skills or food composition knowledge [32]; the weight burden of carrying sufficient food during events; or purposefully limiting intake due to potential gastro-intestinal discomfort associated with high intakes.

It is apparent that athletes need more guidance in order to meet the current recommendations and further research is needed to identify the best way to do this. Additional research is warranted to take into account the type and timing of macronutrient intake, fluid consumption, and the effects of other dietary constituents such as caffeine which have also been shown to improve endurance performance.

\section{Acknowledgments}

We would like to thank the event organizer: Simon Lumley, for his help and support with this study; the participants of the event who kindly gave up much of their time and made this research possible; and John and Sarah Haywood, Lee Mahon, Jackie Richards, Leo Stevenson, Nicola Davies, Ruth Hackett, Ian Lovegrove, Genevieve and Anthony Warburton and Rebecca Gobbi for their assistance with data collection.

\section{References}

[1] A. La Gerche, D.L. Prior, and H. Heidbuchel, "Strenuous endurance exercise: is more better for everyone? Our genes won't tell us." British Journal of Sports Medicine, vol. 45, pp. 412-426, 2011.

[2] H.R. Clark, M.E. Barker, and B,M. Corfe, "Nutritional Strategies of Mountain Marathon Competitors - An Observational Study." International Journal of Sport Nutrition and Exercise Metabolism, vol. 15, pp. 160-172, 2005.

[3] P.N. Ainslie, I.T. Campbell, J.P. Lambert, D.P.M. MacLaren, and T. Reilly, "Physiological and Metabolic Aspects of very Prolonged Exercise with Particular Reference to Hill Walking." Sports Medicine, vol. 35, pp. 619-647, 2005.

[4] R.B. Kreider, "Physiological considerations of ultraendurance performance." International Journal of Sport Nutrition, vol. 1, pp. 3-27, 1991.

[5] N.E. Kimber, J.J. Ross, S.L. Mason, and D.B. Speedy, "Energy balance during an ironman triathlon in male and female triathletes." International Journal of Sport Nutrition and Exercise Metabolism, vol. 12, pp. 47-62, 2002.

[6] J.A. Hawley, E.J. Schabort, T.D. Noakes, and S.C. Dennis, "Carbohydrate-loading and exercise performance: an update.” Sports Medicine, vol. 24, pp. 73-81, 1997.

[7] C.J. Hulston, and A.E. Jeukendrup, A.E. "No placebo effect from carbohydrate intake during prolonged exercise." International Journal of Sport Nutrition and Exercise Metabolism, vol. 19, pp. 275-284, 2009.

[8] J.W. Smith, J.J. Zachweija, F. Peronnet, D.H. Passe, D. Massicotte, C. Lavoie, and D.D. Pascoe, "Fuel selection and cycling endurance performance with ingestion of $\left[{ }^{13} \mathrm{C}\right]$ glucose: evidence for a carbohydrate dose response.” Journal of Applied Physiology, vol. 108, pp. 1520-1529, 2010.

[9] K.L. Osterberg, J.J. Zachwieja, and J.W. Smith, "Carbohydrate and carbohydrate + protein for cycling time-trail performance." Journal of Sports Science, vol. 26, pp. 227-33, 2008.

[10] J. Temesi, N.A. Johnson, J. Raymond, C.A. Burdon, and H.T. O'Connor, "Carbohydrate ingestion during endurance exercise improves performance in adults." The Journal of Nutrition, vol. 141, pp. 890-897, 2011.

[11] American College of Sports Medicine (ACSM), American Dietetic Association \& Dieticians of Canada. "Nutrition and Athletic Performance." Medicine and Science in Sports and Exercise, vol. 41, pp. 709-731, 2009. 
[12] International Olympic Committee (IOC). "IOC consensus statement on sports nutrition 2010." Journal of Sports Sciences, vol. 29:sup1, pp. S3-S4, 2011.

[13] L.M. Burke, and J.A. Hawley, "Effects of short term fat-adaptation on metabolism and performance of prolonged exercise." Medicine and Science in Sports and Exercise, vol. 34, pp. 1492-1498, 2002.

[14] J.A. Hawley, F. Brouns, and A.E. Jeukendrup, A. "Strategies to enhance fat utilisation during exercise." Sports Medicine, vol. 25 , pp. 241-257, 1998.

[15] R.J. Maughan, P.L. Greenhaff, M. Gleeson, C.E. Fenn, and J.B. Leiper, "The effect of dietary carbohydrate intake on the metabolic response to prolonged walking on consecutive days." European Journal of Applied Physiology, vol. 56, pp. 583-591, 1987.

[16] P.N. Ainslie, I.T. Campbell, K.N. Frayn, S.M. Humphreys, D.P.M. MacLaren, and T. Reilly, "Physiological and metabolic responses to a hill walk." Journal of Applied Physiology, vol. 92, pp. 179-187, 2002.

[17] L.G.C.E. Pugh, "Accidental hypothermia in walkers, climbers, and campers: report to the Medical Commission on Accident Prevention.” British Medical Journal, vol.1, pp. 123-129, 1966

[18] M. Kruesman, S. Bucher, M. Bovard, B. Kayser, and p.A. Bovier, "Nutrient intake and performance during a mountain marathon: an observational study." European Journal of Applied Physiology, vol. 94, pp. 151-157, 2005.

[19] K.J. Stuempfle, M.D. Hoffman, L.B. Weschler, I.R. Rogers, and T. Hew-Butler, "Race diet of finishers and non-finishers in a 100 mile $(161 \mathrm{~km})$ mountain footrace." Journal of the American College of Nutrition, vol. 30, pp. 529-535, 2011.

[20] The Longmynd Hike. "The Hike Route." Available at: http://www.longmyndhike.org.uk/hikeroute (Accessed on: 29.11.09).

[21] R.A. McCance, and E.M. Widdowson, "The Composition of Foods", $6^{\text {th }}$ Edition. Food Standards Agency and the Institute of Food Research. Cambridge: Royal Society of Chemistry, 2002.

[22] Abbott. "Optium Blood Glucose Monitoring System: User's Guide." Abbott Laboratories Ltd: Abbott Diabetes Care, 2009.

[23] J.L. Thompson, M.M. Manore, and J.S. Skinner, J.S. "Daily energy expenditure in male endurance athletes with differing energy intakes." Medicine and Science in Sports and Exercise, vol. 27, pp. 347-354, 1995.

[24] L.M. Burke, R.A. Gollan, and R.S.D. Read, "Dietary intakes and food use of groups of elite Australian male athletes."
International Journal of Sports Nutrition, vol. 1, pp. 378-394, 1991.

[25] L.M. Burke, J.A. Hawley, S.H.S. Wong, and A.E. Jeukendrup, "Carbohydrates for training and competition." Journal of Sports Sciences, vol. 29:sup1, pp. S17-S27, 2011.

[26] L.M. Burke, and R.S.D. Read, "A study of carbohydrate loading techniques used by marathon runners." Canadian Journal of Sports Science, vol. 12, pp. 6-10, 1987.

[27] L. Havemann, and J.H. Goedecke, "Nutritional practises of male cyclists before and during an ultraendurance event." International Journal of Sport Nutrition and Exercise Metabolism, vol. 18, pp. 551-566, 2008.

[28] A.L. Carey, H.M. Staudacher, N.K. Cummings, N.K. Stepto, V. Nikolopoulos, L.M. Burke, and J.A. Hawley, "Effects of fat adaptation and carbohydrate restoration on prolonged endurance exercise." Journal of Applied Physiology, vol. 91, pp. 115-122, 2001.

[29] W.M. Sherman, D.L. Costill, W.J. Fink, and J.M. Miller, "Effect of exercise-diet manipulation on muscle glycogen and its subsequent utilisation during performance." International Journal of Sports Medicine, vol. 2, pp. 114-118, 1981.

[30] V.A. Bussau, T.J. Fairchild, A. Rao, P. Steele, and P.A. Fournier, "Carbohydrate loading in human muscle: an improved 1 day protocol." European Journal of Applied Physiology, vol. 87, pp. 290-295, 2002.

[31] P.N. Ainslie, I.T. Campbell, K.N. Frayn, S.M. Humphreys, D.P.M. MacLaren, T. Reilly, and K.R. Weserterp, "Energy balance, metabolism, hydration and performance during strenuous hill walking: the effect of age." Journal of Applied Physiology, vol. 93, pp. 714-723, 2002.

[32] L.M. Burke, G.R. Cox, N.K. Cummings, and B. Desbrow, "Guidelines for daily carbohydrate intake: do athletes achieve them?" Sports Medicine, vol. 31, pp. 267-299, 2001.

[33] K.E. Fallon, E. Broad, M.W. Thompson, and P.A. Reull, "Nutritional and fluid intake in a $100-\mathrm{km}$ ultramarathon." International Journal of Sports Nutrition, vol. 8, pp. 24-35, 1998.

[34] K.E. Black, P.M.L. Skidmore, and R.C. Brown, "Energy intakes of ultraendurance cyclists during competition, an observational study." International Journal of Sport Nutrition and Exercise Metabolism, vol. 22, pp. 19-23, 2012.

[35] L. Laffel, "Ketone bodies: a review of physiology, pathophysiology and application of monitoring to diabetes." Diabetes, Metabolism Research and Reviews, vol. 15, pp. 412-426, 1999.

[36] J.H. Koeshlag, T.D. Noakes, and A.W. Sloan, "Post-exercise ketosis.” Journal of Physiology, vol. 301, pp. 79-90, 1980. 